\title{
EL ÚLTIMO DISCURSO DE JOVELLANOS EN EL REAL INSTITUTO ASTURIANO DE GIJÓN
}

\author{
Marín Teresa (ASO MACHIIADO)
}

Este precioso, aunque incompleto, discurso de Jovellanos se créía desaparecido. Ciopiado por Somoza en 1880, a la vista del manuserito autógrafo que poséja el gijonés don Alejandro Alvargonzález Alvargonzález, la copia es, creo, lo úmien que se conserva, puesto que la mayoría de los papeles de Alvargonzález, que había redido a la liblioteca del Real Instituro Asturiano, desaprarecieron en en incendio del cuartel gijonés de simancas en el verano de 1930 .

La coplia se conserva en la Biblioteca "Jovellanoss de Gijón, Ms. de Jovellanos, mún. LXXIL. Son mueve cuastillas y en la primera locmos los

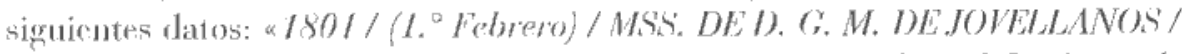
Discurso del cuarto (Certament publico pronuncirudo en el Real Instituto de Gijón el dia 1. de Febrero de 180\%. (borratar antóggrafo) / (inédito) / (Mss.

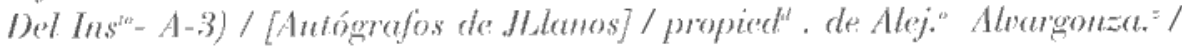
Copia de ful. Somoze en 1580). Asimismo, en la primera cuartilla de texto, segunda de la carpeta, añade don Jolio entre paréntesis: "cuarenta días antes de ir al destierto de Mallorates.

He tratado de encontrar datos de este manuscrito en el Inventario de un jovellanista (1901), en al Catálogo de manuscritos e impresos notables del Instituto de Jovellanos (18893) y en los Nuevos datos (1885) para la biografía de. Jovellanos, obras todas de don Julio Somoza, así como con las Memorias para la vida del Excmo. señor D. Graspar Melchor de Jovellanos (1814) de Ceán Bermúdez. También he rastreado las publicaciones y archivos de (iaso González en busca de alguna noticia. 
No he encontrado denasiadas pistas, y todos parecen olvidarse de este texto, autudo no lo confunden con otros o niegan sencillamente que exista. A Cóm, por ejemplo, no le consta que el certamen se haya celpbrarlo, ni que don Gaspar haya leído discurso alguno. Comete incluso errores cronológicos graves, cuando en las Memorias (pág. 79) dice: "No hay género de aflicriones que no haya sufrido los dos años que permaneció en Cijón, después del ministerio, mchando contra el poder, que le negabr los auxilios, que entonres más que nuncen necesitaba para acabar de vimentar su gran obra de educación. Y continúd diciendo que se cele:braron dos certámenes páblicos más en el Instituto, pero-dice- «es 1800 y 1802 , fecha está úlıima imposible, puesto yue Jovellanos fue hecho prisionero el 13 de marzo de 1801 y en 1802 seguía encarcelado. En al «xtracto de unos diarios», publicato peri Somoza en Nuenos dates, leemos: "Y sigue diciendo [Jovellanos] el cstado en que se halla [el Institu1o], y las persecuciones que de nuevo comienzal a padecer. Piensa en otro cerdamen público; pero a] Diario alabis antes que se verifique, en 20 del propio Enem, dos mests antes de su sorptesa y condución a Mallorcas. Fn electo, el Cinderno IX del Diavio conchye el 20 de cnero de 1801 ; pero el día antes anota Iovenlanos: "Trabajos en las cédulas: allendur, collecha, bebolgar, tremera y en el discurso para thber ol certamen, que scrá muy breves.

No posco, de: nomento, más noticias. Pero me parecía que este texto era sulicicntemente significativo como para darlo a conoces. Y en el cuarto cerlamen, es decir, en la ceremonia de lisenciatura de los alumos y ques ses

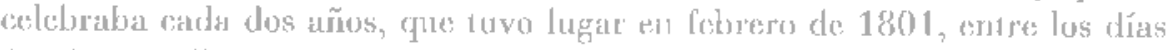

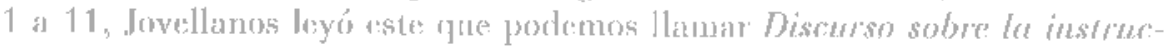
ción pública.

Su recuperación pone en nuestas maros m nuevo texto jovelianista, lan sugerente coum los resiantes, amenue sin huda no corrogido a posteriori por Jovellanos, amo sucodo rou los demás, y en el que se olserval ma cierla desgana en la reducción que dumuesta quizá el estado de ánimo de don Gaspar por atquelias leches. So rata de una disertación algo inquietante y cargada de simbolismo, porque lue el b́lino discurso que pronundió en su Instituto. porque fue quizá, la última vez que Jovellanos dojó volar su imaginación para proclamar sus ideas con rotal libertad. Como ól mismo nos dice, con frase casi profética, el futuro del hombre, "huyendo siempre y alejándose de sus ojos, se los envuclve en espesísimas tinithlas». 


\section{BIBLIOGRAFIA}

Juan Agustín Geßn Bermúdez, Memortas para la vida del Excmo. Ser̃or D. Gaspar Melchor de Jovellanos, y noticirs anatíticas de stas obras, Madrid, Fuentenebro, 1814 .

José Miguel Caso González, Homenaje a Jovellanos en el segundo centenario de la creación det Real Institufo Astuziano de Nántica y Mineralogía, Estudios, edición y notas de José Miguel Caso González, Gijón, 1992.

Agustín Guzman Sancho y José Gonzalo Sancilo FLórliz, El Instituto de Jovellanos, Gijớn, 1993.

Julio Somoza, Jovethanos. Nuenos datos para sre biografü, Madrid, 1885.

Julio Somoza, Catálogo de manuscritos e impresos notables del Instituto de Jovellanos de Gijón, Gijón, 1883.

Julio Somoza, Inventario de un jovellanista, Madrid, 1901. 


\section{"DRSCLIRGO)

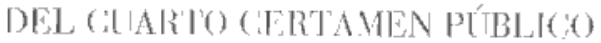

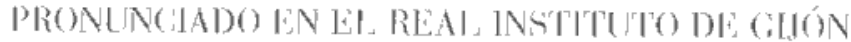 \\ EL DÍA PRIMLRO DOE FIBRERO DE 1801
}

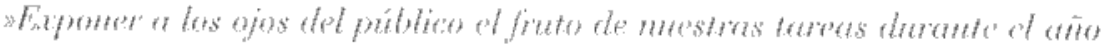

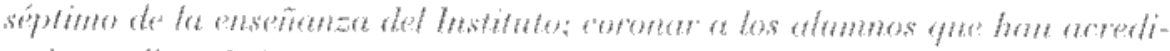

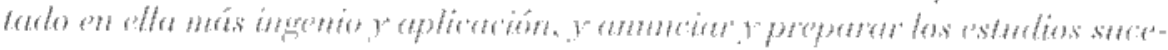

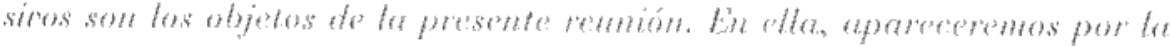

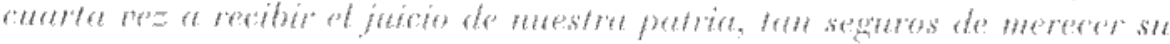

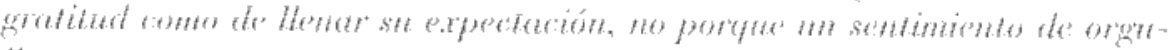

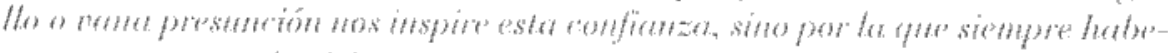

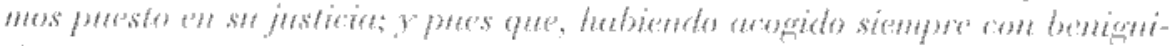

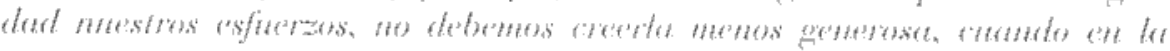

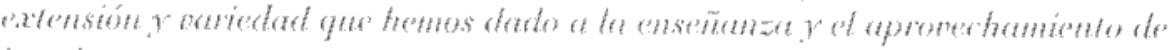

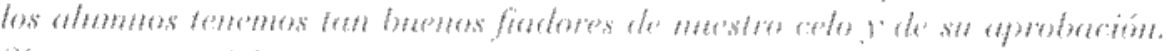

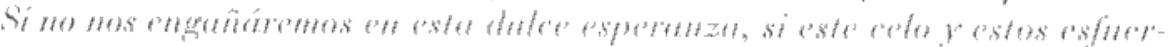

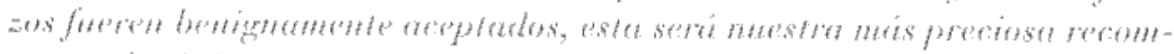

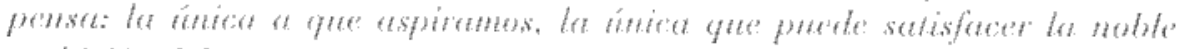
ambicion del patrietismo.

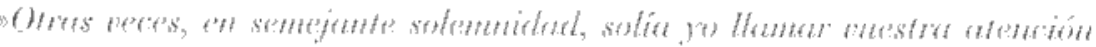

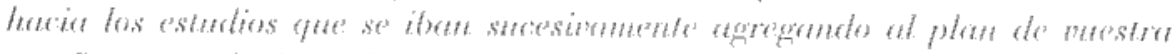

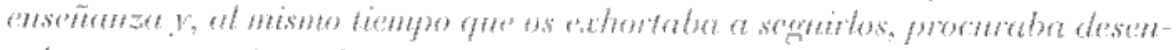

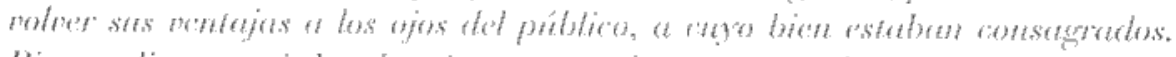

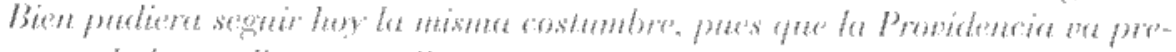

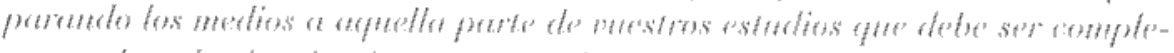

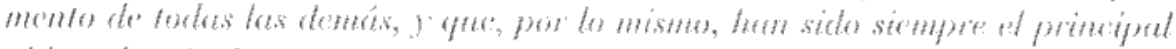

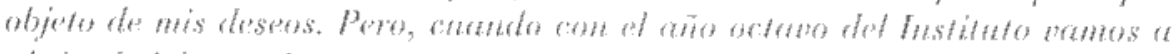

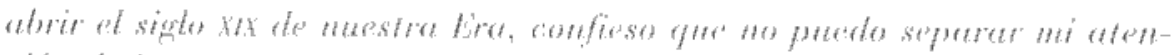

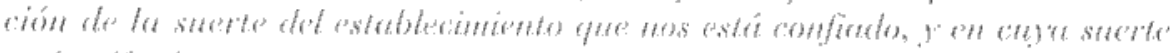

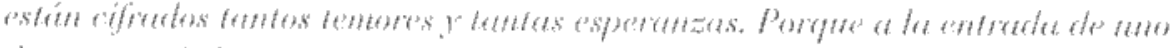

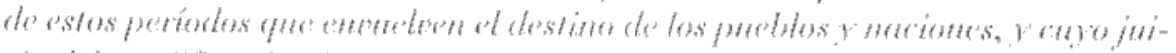

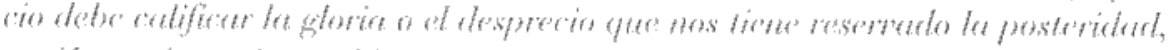

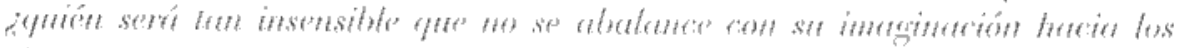

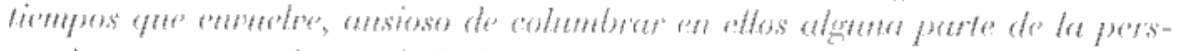

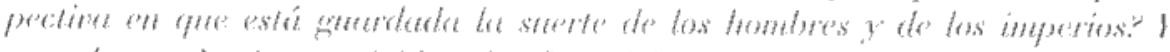

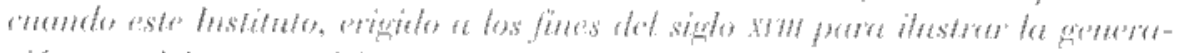

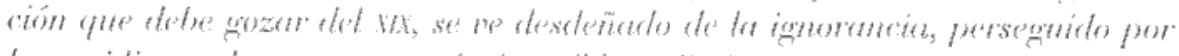

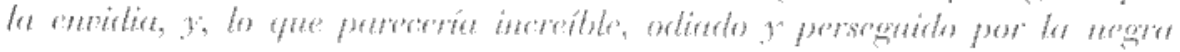


ingratitud, ¿cómo no buscaremos, cómo no trataremos de gozar anticipadamente aquel dulce consuelo que tiene reservado la imparcial posteridad a los que trabajan para ella?

"Yo bien sé que no es dado al hombre penetrar los arcanos de lo venidero. Nacido para respirar breves dias sobre la tierra, parece que la inmensidad de los tiempos pertenece más bien al género humano que a sus individuos. Para estos lo pasado ya no existe. De lo presente, que se desliza en continuo y rápido flujo, apenas puede gozar un instante. Entretanto que el futuro, huyendo siempre y alejúndose de sus ojos, se los envuelve en espesísimas tinieblas. Acaso este es uno de aquellos grandes beneficios en que más se ha señalado la providencia del Altisimo hacia el género humano. Llamado el hombre a vivir en la inmortalidad, para la cual no hay tiempo alguno, parece que su vida es sólo un breve tránsito por ella. Que ella, por tanto, debe ser el blanco de sus acciones, así como el término de su carrera, y que, forzado a olvidar toda la serie de los tiempos, debe pasar rápidamente por ella, suspirando siempre por la inmortalitad a que está destinado.

"Pero este grande objeto, regulador de la conducta del hombre, es el que Ilama poderosamente su atención a la contemplación de los entes y los sucesos, cuya rúpida sucesión mide y señala los tiempos. En este flujo por la contemplación de lo pasado, juzga de lo presente, y en el conocimiento del presente, busca la previsión que le debe conducir en lo futuro. Así, la Providenciat dio al hombre en su razón, así como nua balanza para pesar los sucesos, un anteojo para prevenirlos, y en ambos puso los instrumentos de la prudencia humana, de esta antorcha que debe alumbrar el hombre en todas sns acciones, diriginle en todos sus juicios y conducirle en el áspero camino de la vida, al término que debe proponerse en ella.

"Permitid, pues, que siguiendo esta luz, busque yo por un instante la suerte de mi establecimiento en cuya prosperidad están cifrados los más preciosos intereses. Yo deseo llanar hacia ellos vuestra atención y la del público. iAht - Demasiado dolorosa es para nuestro corazón esta tibia indiferencia, si ya es un frio desdén con que son mirados el ardiente celo con que luchamos por conservarlos y promoverlos! Demasiado funestos son para este mismo público a quien están consagrados! Ojalá que conociendo algín dia todo su valor, los busque con toda el ansia que merecen! jojalá que recogiéndolos y enriqueciéndose con ellos, nos haga aquella justicia que, aunque tardúa, será la mejor recompensa de nuestro relo!

"Pero, jacaso cabe en la prudencia humana antever unos bienes que se hallan a tanta distancia de nuestros ojos? ¿Cabe pronosticar anax ventajas 
gue se hallan expuestas a tantas contingencias? Demasiado ciestos son esta incertidumbre y este riesgo. Pero, jpor qué no padremos lees en la historia de las instituciones pasudas el destino de las presentes? ¿Por qué, indagando las causas de la prosperidad y la mina con la organización de las otras, no podremos columbra algith parte de su futuro destino. Esto, por lo menos, es lo gue cabe en nuestra previsión. Fsto lo grep, por wn mato, servina de materin al presente disturso.

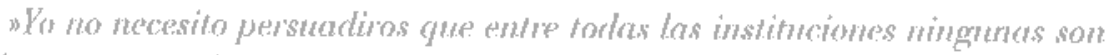
tan importantes, mingumas mús prowechosas gue las que están consagradras a la instrnctión. Esta es man verdad de nadie desconocida, anmque, por desgracia, apreciada de poros. Si el hombre, como decía el gran Bacon, vale lo que sabe,

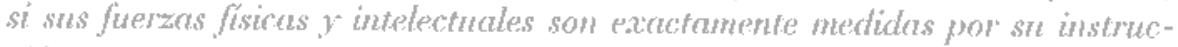
ciom, en nua palabra, si la instnación bien entendida no puede ser olra cosa que la rentión de los conorimientos necesurios a la perfección de su ser qquién suré el que no conozca los bienes que están rifrados en la instrucción priblica"

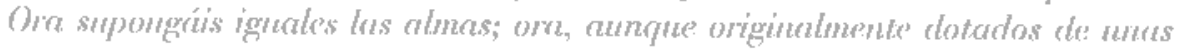

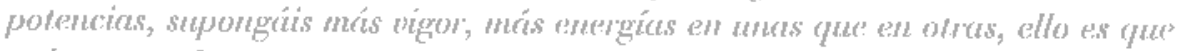
lodas se perfeccionan por la instrucción. La instrucción las ilustra y las ent-

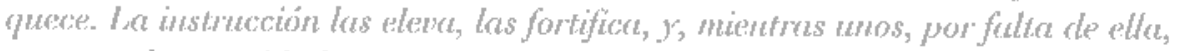

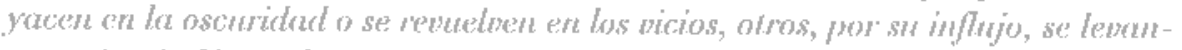

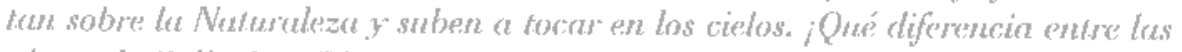
almas de Chliugula y Sócrates, qué distancia entre las de Osmán' y Nesuton!

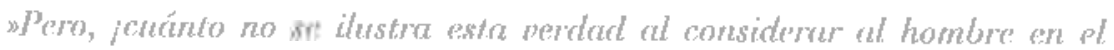
estado sociall La instrucrión, que' formó las sociedades, es la única que pacde. consemwlas y hatertas florecer. El hombre no pado instruirse sin sentir la ven-

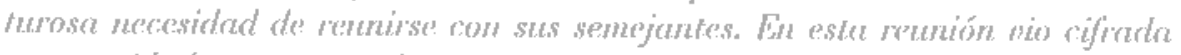

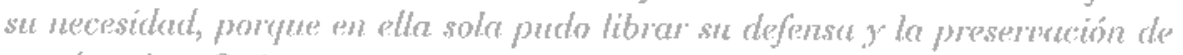
sus derechos. Se impuso, es vesdad, nueves obligationes, pero estus obliguciostes estan staves por la benuidad de los sacrifuios que exigian; dulees por la preciosidad de los bienes que consemabun, y fáciles de desenupeñu por sn con-

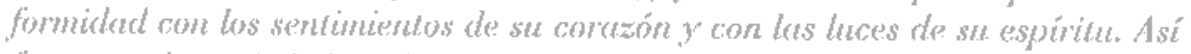

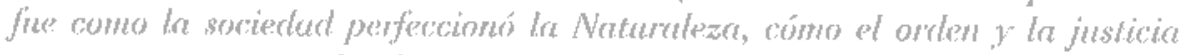

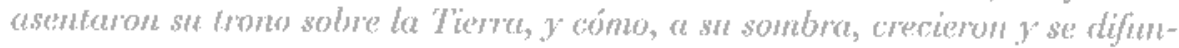
dieron por ellas las virtudes sociales, el amor; la compasión, la beneficencia, estas vintudes yue haren el consuelo y la gloria de la hamanidad.

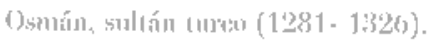




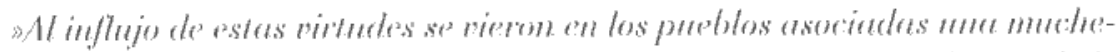

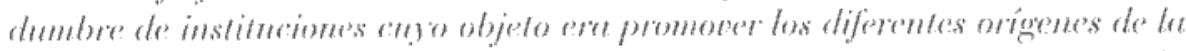

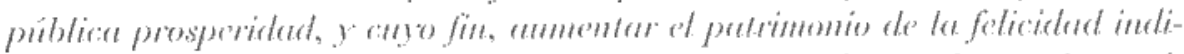

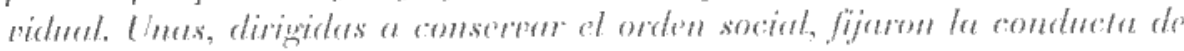

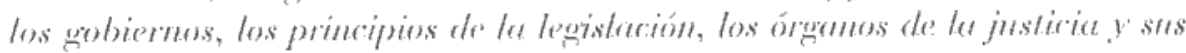

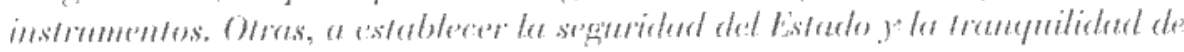

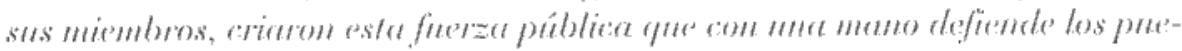

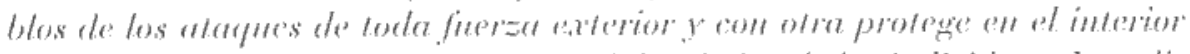

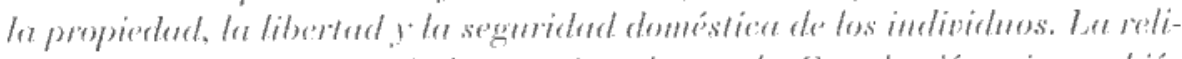

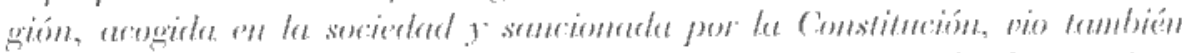

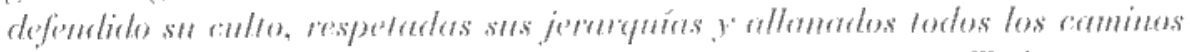

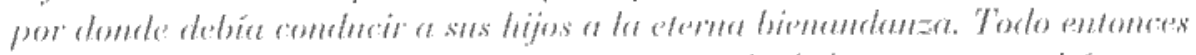

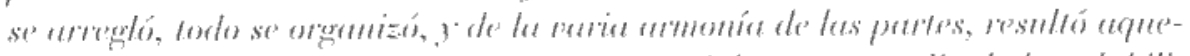

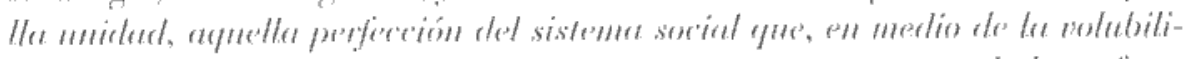

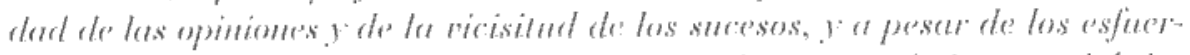

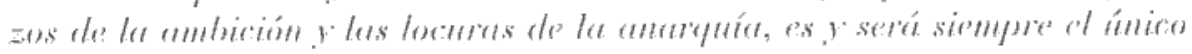

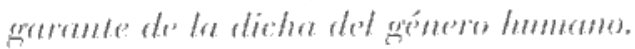

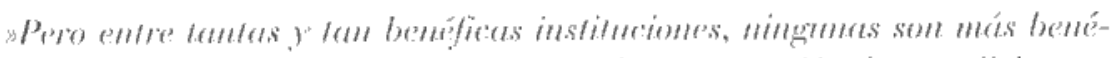

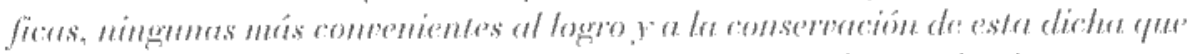

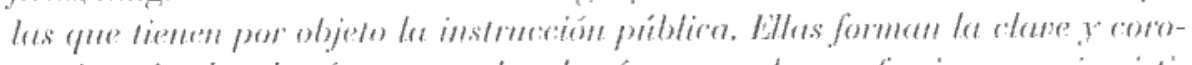

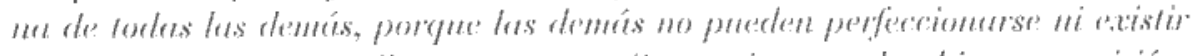

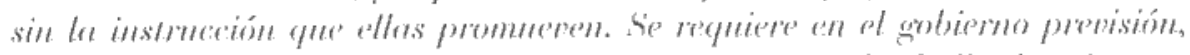

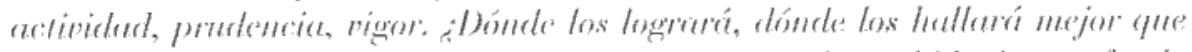

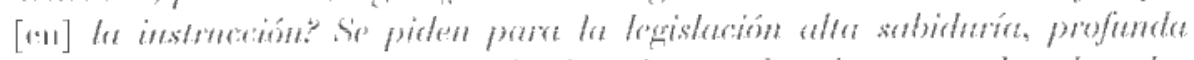

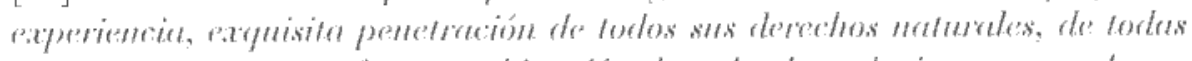

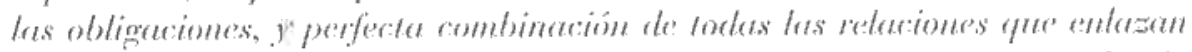

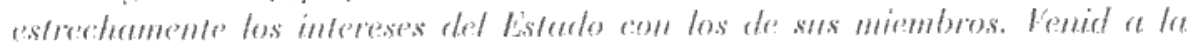

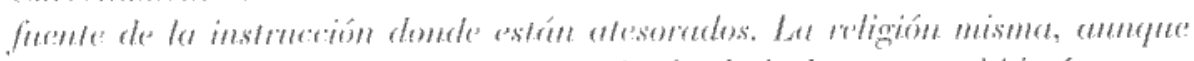

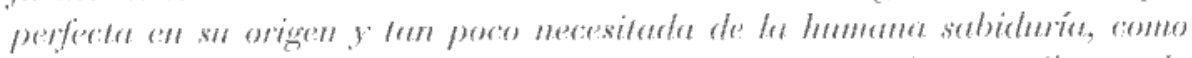

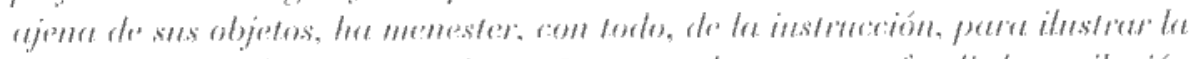

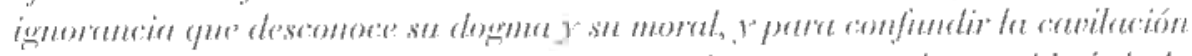

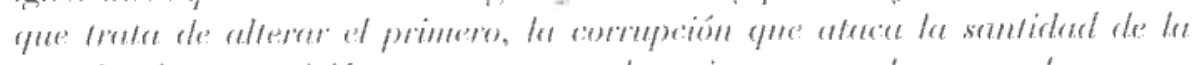

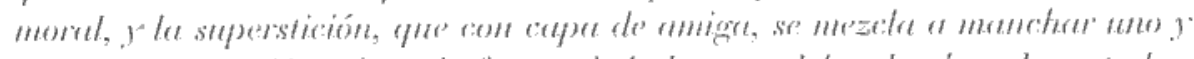

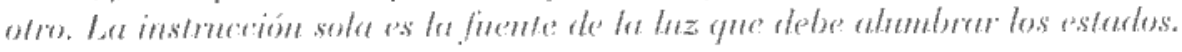

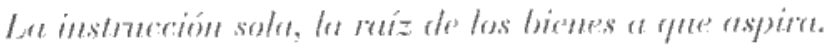

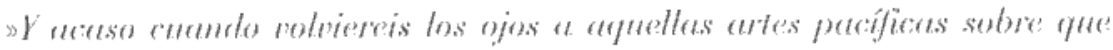

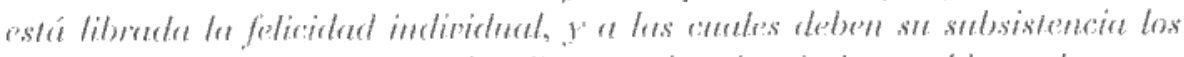

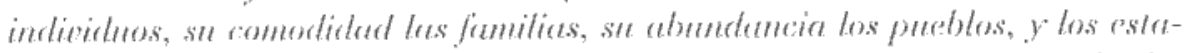

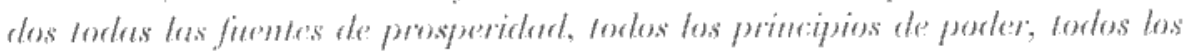


medios de seguridad y preservación; cuundo volváis a ellas los ojos, jno hallarets su suerfe librada enteramente sobie la instrucción?

"Llla es la que, bajo los nombres de culture, rivilidad, ilustración, educación reunió los pueblos en aguel centro de midad a que la Natualeza llamaba al hombre. Ella la que, hbrundo sobre su industria el socomo de sus necesidades y el logro de sus placeres, le endulzó el trabajo y hizo de él la prenda de su felicidad. Ella la que, despertando st interés y conduciendo continuanente a este fon, le hizo divigu a él todas sus haces. mplear en él todas sus

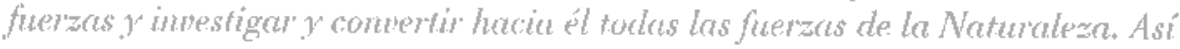
nacieron las artes necesarias, estas ates sublimes por las cuales ol hombre se levantó sobre fodos los seres y dominó sobre la Naturaleza entera. Así nacieron las artes atiles; estas artes útiles a que debe la especie humana bienes tan preciosos, placeres tan sublimes. Asi, en fin, nacieron lis Bellas Artes, gloria y reveo de la sociedad, esplendor y omamento de los pueblos, delicia de las almas semsibles y gloria del género humano.

"En efecto, ¿qué erra del génervo hamano antes de la moneción de todes estas artes." Oné era la Natumleza pona el hombre en su primitiva ignorancire? La liema, liena de espesos bosques, o de hondas lagmas y prontanos, cerraba por todas partes sus pasos y abandonada a las feroces bestion y a los

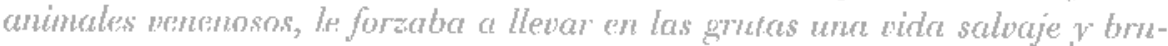
lat. Cubierta de abrojos y malezas apenas le presenaba en acerbos y sibestres fratos un escaso y insalubre alinento. El hombre entonces, ignorante de la axelencia de su ser, no conociendo ninguno do los vínculos que le unín a su especia, ninguno de los medios de establecer la dominación a yue estaba lamado en conuin, sin religión, sin sociedad, sin principio ni regla alguna de

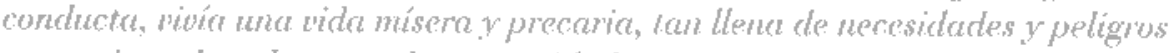
como ajena de todo consuelo y seguridad.

"Pero la instrucción rayó, a su inflyjo nació la agricultura y con ella la gloria del hombre $y$ la Nuturaleza. Su mano, entomces, abatió los bostues, desuguó los lagos, refrenós los rios y aseguró todos los pspacios de su deminio. Conuertido a mejorarle, minós al cielo, estudió los tiempos, dividió las estutunes y fijó los períodos y los objetos de su trabrio. Animales dóciles y robustos rinieron en su auxilio, unos para ayudarle en sus labores y atros para entquecerte ron sus esquilmos. La plección de temeno, la elecrión de semillas, la invención de instrumentos y métodos perfeccionó este arte, y la tierra sacó entonces de su seno cuanto pedín el deseo y la codicia del hombre. La esperie. humana llenó entonces todos sus ángulos. Reunida en alquerias, en bariadas, en pueblos, se amontonó al fin en las grandes ciudades. En ellas, Levantó tem- 
plos a la religión y a la justicia. Palacios a la soberanía y al poder, asilos a la industria, a la pobreza y a la enfermedad; domicilios a las artes y a las letras. Y porque no era dado al hombre gozar del bien sin alguna mezcla de mal, levantó también fortalezas para reprimir o encerrar el vicio y asilos para socorrer la pobreza y la enfermedad. Ved aqui la obra de la instrucción. Ved aqui la cultura, a que el hombre debía ser conducido por ella.

"Yo no os citaré la enumeración de las artes que la instrucción dictó al hombre, para dar forma y valor a las producciones de la Naturaleza $y$ mientras las proporcionaba a las necesidades, al regalo y al placer del hombre, servian de ocupación a la más numerosa porción de su especie, y de apoyo a la subsistencia de sus familias.

[sin terminar] 